\title{
EPIDEMIOLOGY OF HUMAN AND ANIMAL TRICHINELLOSIS IN ITALY SINCE ITS DISCOVERY IN 1887
}

\author{
POZIO E.*, LA ROSA G.* \& GOMEZ MORALES M.A.*
}

\section{Summary :}

The epidemiology of trichinellosis in Italy is characterised by a sylvatic cycle present only on the mainland. The domestic cycle probably never existed, though a domestic focus occurred on the island of Sicily between 1933 and 1946. The red fox is the main reservoir, with the prevalence of infection ranging from $0.0 \%$ in lowlands to $60 \%$ in the Alps. The main etiological agent is Trichinella britovi. Trichinella pseudospiralis has been detected in two birds. From 1948 to March 2000, trichinellosis was diagnosed in 1,347 persons, who acquired the infection in 21 outbreaks.

KEY WORDS : humans, animals, trichinellosis, epidemiology, Italy

\section{TRICHINELLOSIS IN HUMANS}

In n Italy, the history of human trichinellosis can basically be divided into three major periods: 1) the period in which the first reports were published; 2) the period of outbreaks in Sicily; and 3) the period of outbreaks on mainland Italy (i.e., after World War II to the present) (Pozio, 1991). Specifically, the first reports of individual cases and the first outbreak date back to the end of the 19th century and the beginning of the 20th century (Table I). The first human Trichinella infection was detected in 1887 during an autopsy on a woman who had died for other reasons. The first trichinellosis outbreak occurred during World War I for the consumption of pork; two persons died, and to date, no other deaths from trichinellosis have been reported on mainland Italy. Epidemiological investigations conducted at that time suggested that the infected pig was bred with infected pork remnants brought to Italy by Austrian soldiers after Italy's defeat at Caporetto.

Between 1933 and 1946, four severe outbreaks occurred in Sicily for the consumption of pork (Table II). Epidemiological investigations carried out at that time showed that the source of the infection was sausages

* Laboratory of Parasitology, Istituto Superiore di Sanità, viale Regina Elena 299, 00161 Rome, Italy.

Correspondence: E. Pozio, Istituto Superiore di Sanità, viale Regina Elena 299, 00161 Rome, Italy.

Tel.: +390649902304 - Fax+390649387065 - e-mail: pozio@iss.it from pigs bred on family farms in Montemaggiore Belsito, a village near Palermo, Sicily's capital city. This epidemic focus came to an end only in 1961, when the last infected pig was found at slaughtering. Thirtysix years later, the parasite isolated from tissue samples of the last infected pig was identified as Trichinella spiralis by polymerase chain reaction (Pozio \& La Rosa, 1998). Since then, no other focus of domestic trichinellosis has been documented in Italy. The most reasonable explanation for the presence of $T$. spiralis in Sicily, which is free of trichinellosis in wildlife, is that pork or pork products (e.g., sausage and salami) infected with T. spiralis were brought to Sicily from persons who had emigrated to the United States and then returned home. It is well known that in the 1930s, hundreds of thousands of persons emigrated from Sicily to the United States, where domestic trichinellosis was a common infection in pigs. Leftovers of this infected food could have been ingested by domestic pigs, establishing a domestic focus on this island.

\begin{tabular}{clcc}
\hline Year & Region (town) & $\begin{array}{c}\text { No. of infected } \\
\text { persons/deaths }\end{array}$ & $\begin{array}{c}\text { Source } \\
\text { of infection }\end{array}$ \\
\hline 1887 & Marche (Camerino) & $1 / 0$ & $?$ \\
1900 & Piedmont (Ozegna) & $1 / 0$ & pig \\
1912 & Venetian (Padova) & $1 / 0$ & pig \\
1917 & Lombardy (Bergamo) & $20 / 2$ & pig \\
1930 & Piedmont (Novara) & $1 / 0$ & $?$ \\
\hline
\end{tabular}

Table I. - First single human infections and the first outbreak of trichinellosis in Italy.

\begin{tabular}{llcc}
\hline Year & \multicolumn{1}{c}{ Region (town) } & $\begin{array}{c}\text { No. of infected } \\
\text { persons/deaths }\end{array}$ & $\begin{array}{c}\text { Source of } \\
\text { infection }\end{array}$ \\
\hline 1933 & Sicily (Casteltermini) & $80 / 5$ & pig \\
1942 & Sicily (Villafrati) & $30 / 4$ & pig \\
1945 & Sicily (Montemaggiore Belsito) & $84 / 13$ & pig \\
1946 & Sicily (Caccamo) & $15 / 0$ & pig \\
\hline
\end{tabular}

Table II. - Human infections with Trichinella spiralis for the consumption of pork from domestic pigs from the focus of Montemaggiore Belsito (Palermo). 


\begin{tabular}{|c|c|c|c|c|}
\hline Year & Region (town or city) & No. of infected persons & Source of infection & Etiological agent \\
\hline 1948 & Latium (Rome) & 109 & pig & $?$ \\
\hline 1953 & Umbria (Vallo di Nera) & 9 & pig & $?$ \\
\hline 1961 & Trentino Alto Adige (Canale S. Bovo) & 9 & fox & $?$ \\
\hline 1968 & Apulia (Mattinata) & 9 & pig & T. britovi \\
\hline 1975 & Emilia Romagna (Bagnolo in Piano) & 90 & horse* & T. britovi \\
\hline 1978 & Basilicata (Oliveto Lucano) & 6 & wild boar & ? \\
\hline 1980 & Calabria (Sila) & 3 & pig & T. britovi \\
\hline 1984 & Lombardy (Varese) & 13 & horse $^{*}$ & $?$ \\
\hline 1985 & Apulia (Gravina di Puglia) & 80 & wild boar & T. britovi \\
\hline 1985 & Calabria (Cosenza) & 2 & fox & T. britovi \\
\hline 1986 & Basilicata (Irsinia) & 20 & wild boar & T. britovi \\
\hline 1986 & Emilia Romagna (Salsomaggiore) & 300 & horse $^{*}$ & T. britovi \\
\hline 1988 & Umbria (Polino) & 48 & wild boar & T. britovi \\
\hline 1990 & Piedmont (Ovada) & 11 & wild boar & T. spiralis \\
\hline 1990 & Apulia (Barletta) & 500 & horse* & T. spiralis \\
\hline 1991 & Basilicata (Grassano) & 6 & pig & T. britovi \\
\hline 1993 & Tuscany (Montevarchi) & 4 & pig & T. britovi \\
\hline 1995 & Abruzzo (Castel di Sangro) & 23 & wild boar & T. britovi \\
\hline 1996 & Basilicata (Villa d'Agri) & 3 & pig & T. britovi \\
\hline 1996 & Abruzzo (Popoli) & 10 & wild boar & T. britovi \\
\hline 1998 & Emilia Romagna (Piacenza) & 92 & horse $^{*}$ & T. spiralis \\
\hline 2000 & Apulia (Bitonto) & 36 & horse $^{*}$ & T. spiralis \\
\hline
\end{tabular}

*Imported animals

Table III. - Human outbreaks of trichinellosis occurring after Word War II to the present (no deaths occurred).

In the period beginning after World War II and continuing to the present, all outbreaks and single cases have occurred on mainland Italy (Table III) (Pozio et al., 2000). During this period, changes in the epidemiological picture of human trichinellosis in Italy have been brought about by improvements in pig-breeding practices, increases in wild boar populations, and the consumption of horse meat imported from countries with high endemicity for domestic trichinellosis. In fact, the source of human infections, which, until the 1970s, was mainly pork from domestic pigs, currently represents only a small percentage of total infections. Consumption of raw meat of horses imported from the former Yugoslavia, Poland and Serbia has accounted for approximately $75 \%$ of infections, and consumption of pork of domestic pigs and domestic wild boars has accounted for $18.1 \%$ of infections. All infected animals but one were autochthonous. These swine acquired Trichinella infection from the sylvatic cycle. In fact, all of these animals were bred with carcasses of foxes. Only $6.5 \%$ and $0.8 \%$ of human infections were related to the consumption of meat from wild boars and foxes hunted for sport, respectively. All infections due to the consumption of local animals (i.e., pigs and wildlife) were caused by $T$. britovi, whereas most infections due to the consumption of imported animals (i.e., horses and a wild boar) were caused by $T$. spiralis. In the same period (1948-2000), trichinellosis was diagnosed in 63 persons who acquired the infection abroad (Eastern Europe, South-East Asia, and South America) and in 11 persons for whom the source of infection was unknown.

\section{TRICHINELLOSIS IN ANIMALS}

\section{WILDLIFE}

T $\mathrm{n}$ the past 15 years, all but three of the sylvatic animals infected with Trichinella have been found to 1 harbour T. britovi; one fox (Vulpes vulpes) harboured T. spiralis, which was shot $100 \mathrm{~m}$ from the French border, and two sedentary night-birds of prey (a tawny owl, Strix aluco, and a little owl, Athene noctua) were infected with T. pseudospiralis (Pozio et al., 1999). Of the 3,565 foxes examined for Trichinella, 155 have been found to be positive (prevalence ranging from $3 \%$ to $35 \%$ ). The infected animals originated from natural habitats above $500 \mathrm{~m}$ asl or from mountainous areas or natural parks at lower altitudes (Pozio et al., 1996) (Table IV). The prevalence of infection in wolves (Canis lupus) has been reported to be $30.9 \%$, though infected wolves have only been

\begin{tabular}{lccc}
\hline \multirow{2}{*}{\multicolumn{1}{c}{ Host }} & \multicolumn{2}{c}{ Positive/examined (\%) } & \\
\cline { 2 - 3 } \multicolumn{1}{c}{$<500 \mathrm{~m}$ asl } & $>500 \mathrm{~m}$ asl & \\
\hline Fox & $4 / 1,627(0.2)$ & $151 / 1,938(7.8)$ & $\mathrm{p}<0.001$ \\
Wolf & $0 / 24$ & $25 / 57(43.8)$ & $\mathrm{p}<0.001$ \\
Beech marten & $0 / 34$ & $2 / 55(3.6)$ & - \\
Badger & $0 / 15$ & $3 / 19(15.7)$ & - \\
Stray dog & $0 / 157$ & $3 / 274(1.0)$ & $\mathrm{p}<0.01$ \\
Wild boar & $0 / 24 \times 10^{4}$ & $9 / 13 \times 10^{4}(0.006)$ & $\mathrm{p}<0.001$ \\
\hline
\end{tabular}

Table IV. - Relationships between trichinellosis in sylvatic animals and altitude (asl: above sea level). 
found in natural habitats above $500 \mathrm{~m}$ asl. Of 156 mustelides tested, three badgers (Meles meles) and two beech martens (Martes foina) were found to be positive for Trichinella, and all of them originated from mountainous areas above $600 \mathrm{~m}$ asl. An isolate was obtained from a brown bear (Ursus arctos marsicanus) originating from the National Park of Abruzzo at $1,100 \mathrm{~m}$ asl. Trichinella britovi larvae were isolated from stray dogs killed in the mountains of the Basilicata region at $600-750 \mathrm{~m}$ asl. In the past fifteen years, approximately 560,000 wild boars (Sus scrofa) have been killed by hunters, but only eleven animals were found to be positive for Trichinella. Of the 1,547 rodents trapped in mountain areas, five brown rats (Rattus norvegicus) were found to be infected with Trichinella larvae, and all five were found in two garbage dumps located at $450 \mathrm{~m}$ asl in a mountainous area of Abruzzo; an infected black rat (Rattus rattus) was found in a farm where a Trichinella-infected wild boar had been bred. Trichinella larvae were not found in 132 insectivores trapped in mountain areas, where the prevalence of trichinellosis in the vulpine population was higher than $10 \%$. Trichinella-positive animals were collected from mountainous areas with an average population density of 73 inhabitants $/ \mathrm{km}^{2}$, whereas Trichinella-negative animals were collected from lowland areas with 238 inhabitants $/ \mathrm{km}^{2}$.

\section{DOMESTIC ANIMALS}

Of the approximately 12 million domestic pigs slaughtered each year in Italy, since 1958, when the examination of all slaughtered pigs become compulsory, only nine animals raised in open pastures in mountainous areas have been found to be infected with $T$. britovi. The sporadic detection of Trichinella infection in domestic cats and dogs was found to coincide with human outbreaks (Pozio, 1998).

\section{CONCLUSIONS}

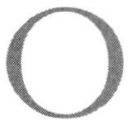

nly the sylvatic cycle is currently present in mountainous areas and natural parks of mainland Italy, whereas lowlands and all Mediterranean islands are Trichinella-free. The prevalence of infection in wild boars is very low $(0.006 \%)$ as in domestic pigs bred in contact with wildlife in mountain areas. Domestic pigs bred on modern industrialised farms have never been found to be infected with Trichinella. Although the prevalence of infection in swine bred on organic or ecological farms is very low $(0.001 \%)$, most of these animals are not routinely examined for Trichinella at the slaughterhouse. Trichinella pseudospiralis has only been detected in two birds, but its presence in Italian mammals is strongly suspected. Most human infections (75\%) are caused by the consumption of horse meat imported from Eastern Europe, whereas human infections for the consumption of domestic and sylvatic animals account for only $25 \%$. The finding that most infections for the consumption of pig and wild boar meat occur in the winter, during which other viral infections are most common, may have resulted in trichinellosis often being misdiagnosed, especially in the past, when serodiagnosis did not exist and when the incidence of the infection is assumed to have been higher, given that pig-rearing was practised by many families. Since 1983, when a passive surveillance of human trichinellosis cases and a free-of-charge serological service were established at the Istituto Superiore di Sanità, the number of documented outbreaks has increased considerably. However, we cannot exclude that in recent decades the transmission pattern has changed due to increases in the wild boar population, the breeding of wild boars and pigs on organic farms and an increase in infected horses imported from abroad.

\section{ACKNOWLEDGEMENTS}

Whis work was made possible by the support received from the surveillance project on emerging and re-emerging infectious diseases. Istituto Superiore di Sanità Art.502/12, Ministry of Health of Italy.

\section{REFERENCES}

Pozio E. La trichinellosi in Italia. Notiziario dell'Istituto Superiore di Sanità, 1991, 4, 2-3.

Pozio E. Trichinellosis in the European Union: epidemiology, ecology and economic impact. Parasitology Today, 1998, $14,35-38$

Pozio E., Goffredo M., Fico R. \& LA Rosa G. Trichinella pseudospiralis in sedentary night-birds of prey from Central Italy. Journal of Parasitology, 1999, 85, 759-761.

Pozio E. \& LA Rosa G. Identification of the likely etiological agent of human trichinellosis in Sicily (Italy) between 1933 and 1946. American Journal of Tropical Medicine and Hygiene, 1998, 59, 906-907.

Pozio E., la Rosa G., D’Ancona F., Amati M., Mancini BerBIERI F. \& De GiACOMO M. International Trichinella Reference Center. Notiziario dell'Istituto Superiore di Sanità, $2000,13,1-4$

Pozio E., La Rosa G., Serrano F.J., Barrat J. \& Rossi L. Environmental and human influence on the ecology of Trichinella spiralis and Trichinella britovi in Western Europe. Parasitology, 1996, 113, 527-533. 